\title{
La configuración de la realidad en dos momentos de la obra de Paul Zech
}

Tomás Sufotinsky ${ }^{1}$

\section{Resumen:}

Es posible revisar algunos conceptos de la estética marxista, principalmente vinculados con propuestas teóricas de György Lukács y de Theodor Adorno en dos textos históricamente distantes de la obra del autor alemán Paul Zech (1881, Briesen, Prusia - 1946, Buenos Aires): Das schwarze Revier (1913) y "Buenos Aires" (1935). En el transcurso de los veintidós años que separan un texto del otro, se pueden observar variaciones sobre los procedimientos de reflexión de la realidad y de la configuración formal de la obra en este autor vinculado a la ideología marxista.

Palabras clave: Paul Zech; Realismo; Lukács; Adorno.

\section{The configuration of reality in two moments of Paul Zechs work}

\begin{abstract}
:
It is possible to revisit some concepts of Marxist aesthetics -mainly associated to the theoretical proposals of Gyorgy Lukacs and Theodor Adorno- in two productions by the German author Paul Zech (1881, Briesen, Prusia - 1946, Buenos Aires): Das schwarze Revier (1913) and 'Buenos Aires' (1935). Throughout the period of twenty-two years between the first and the second piece, it is possible to appreciate changes over the procedures of reflection of reality and formal configuration within the work of this author linked to Marxist ideology.
\end{abstract}

Keywords: Paul Zech; Realism; Lukacs; Adorno.

En la obra de Paul Zech (1881, Briesen, Prusia - 1946, Buenos Aires) es posible observar una serie de conceptos de la estética marxista que nos permiten, por un lado, ensayar su aplicabilidad en el transcurso histórico y el traslado de un mismo autor a contextos en extremo diversos y, por otro, introducir el estudio de su obra a un horizonte teórico que, creemos, es más que propicio y favorable para su abordaje.

\footnotetext{
${ }^{1}$ Poeta, licenciado em Letras pela Facultad de Humanidades y Artes da Universidad Nacional de Rosario.E-mail: tomas.sufotinsky@gmail.com.
} 
Podríamos dividir la obra de Zech en tres grandes momentos: el primero, caracterizado por sus traslados dentro de Alemania con motivo de diversos estudios y ocupaciones laborales, que repercutirían en su prolífica obra temprana (finalmente se instalaría en Berlín en 1912); esta primera etapa abarcaría desde los últimos años del siglo XIX hasta fines de la década de 1910. En el segundo momento, correspondiente a la tercera década del siglo y primeros años de la cuarta, hay una producción no tan difundida como la de la primera etapa; momentos de precariedad económica y conflictos legales y, sobre todo, políticos que lo llevan a, en 1933, exiliarse en Argentina, donde comenzaría la tercera y última etapa de su obra, que culminaría con su muerte en Buenos Aires en 1946. Este último periodo está marcado por sus intentos de subsistencia por medio de ayudas económicas de allegados y becas de las instituciones ligadas a los sectores antifascistas de la colectividad alemana. Durante estos años hay una gran producción publicada fragmentariamente en medios gráficos alemanes que se imprimían fuera de Alemania para evitar la censura (Die Sammlung, por ejemplo, fue publicada en Ámsterdam), medios de la colectividad alemana en Argentina (Argentinisches Tageblat) y Chile (Deutsche Blätter). En este momento, Zech se ocupa, entre otros temas, de retratar y criticar los sucesos contemporáneos en la patria dejada y de dar una imagen de una tierra hasta entonces ignota a la que llegó apresuradamente y sin mucha premeditación ${ }^{2}$.

Nuestra intención es aquí la de tomar dos textos de su obra distantes entre sí, primero un volumen de poemas publicados hacia 1913 en Berlín en los que se dedica a retratar la vida de los obreros en las minas de carbón, Das schwarze Revier (El negro distrito), y luego un ensayo en el que vuelca las primeras impresiones que tuvo de su llegada a Buenos Aires en 1933. Pretendemos revisar estos dos puntuales momentos de su obra buscando en ellos la posibilidad de leer categorías de la teoría literaria ligada la estética marxista, como son la representación de la complejidad del entramado social superficial en vinculación a lo subyacente con lo que se interdeterminan (en contra de un esencialismo unívoco que desdeña las relaciones dialécticas apariencia-esencia) y la representación de personajes tipo. A sabiendas de que esto significa en algún punto un forzamiento de la teoría planteada principalmente- por Lukács, pues no sólo se sale del corpus específico planteado por él, sino que diverge incluso genéricamente de su concentración en la novela, pensamos que estas categorías pueden resultar operativas y útiles para estudiar la obra de Zech. Asimismo, creemos que la cualidad de fragmentarios de estos textos -sobre todo del ensayo que trataremos, "Buenos

2 Cabe destacar que la gran mayoría de los escritores e intelectuales exiliados de la Alemania del III Reich buscaron asilo en Estados Unidos o en los países neutrales de Europa. El caso de Zech en Argentina constituye una rareza en este sentido; el colega y compatriota más cercano puede decirse que fue el caso más famoso de Stefan Zweig en Brasil. 
Aires"- y la propia búsqueda de una forma en la que encauzarse pueden permitirnos vincularlos también a las propuestas en torno a la forma del ensayo y su cualidad de fragmentario y no totalizante planteadas por Adorno en "El ensayo como forma" (publicado en Notas de literatura).

En 1913 Zech publica en Berlín un volumen de 13 poemas llamado El negro distrito. Allí presenta a la manera del Dinggedicht (poema-objeto) y -a pesar de no rehuir al uso de recursos poéticos- con un tono eminentemente realista, una imagen de la vida de los mineros de la industria carbonera. 3 Héctor Piccoli define el Dinggedicht como

la aprehensión contemplativa de un objeto. Este "objeto" puede ser incluso un ser vivo - animal o planta- o una obra de arte. Más que "describir" o "representar" el objeto, el poema lo presenta, por medio del ajustado despliegue de recursos formales, con una patencia tal, que nos parece estar viéndolo y/u oyéndolo, es decir captándolo por vía de la percepción sensorial directa (PICCOLI, 2010, 9-10).

Rilke, asimismo, tal vez uno de los mayores exponentes de este tipo de poema en la lírica alemana, plantea la autonomía del objeto en el poema -lo que él llama objetividad- de la intromisión de un Yo que lo interprete (OVERATH, 1987). Partiendo de la observación de la pintura de Cézanne, en la que por la cohesión cromática se sustentaría la autonomía u objetividad de la pintura (que prescinde ya de la línea), en el poema, esta autonomía del objeto estaría dada, como plantea Piccoli, por "el ajustado despliegue de recursos formales". La preocupación aquí es por la emergencia del poema como artefacto, una "cosa" independiente, una obra cuya factura lo hace ingresar como si fuera un objeto al mundo: revelación de aquello que se presenta ante los sentidos. Pero esta idea no debiéramos entenderla como una evasión del autor en términos ideológicos y un mero "esencialismo" de la obra. $\mathrm{El}$ autor elige aquello del mundo a presentar en el poema (o tal vez mejor sea decir aquello que el poema presente o que se presente en/por medio del poema) y el poema-objeto aflora ahí gracias a su ajustado despliegue de recursos formales, viviendo en sí, si se trata, como nosotros creemos en el caso se Zech, de un autor realista, "la insobornable y humilde honradez estética" con la que la obra se compromete con los asuntos humanos (LUKÁCS, 1968, p. 226). Es decir, en la objetividad planteada por el Dinggedicht de Zech, como veremos -así como lo plantea Rilke-, hay un Yo que, si bien está desaparecido o escindido, no niega sin embargo su tendencia, como sí se pretenderá que suceda con posterioridad, por ejemplo, con la fotografía de la Neue

3 Zech ha sido muy esquivo respecto a sus datos biográficos llegando incluso a falsearlos, por lo cual los datos que se tienen sobre esta etapa de su vida no son del todo confiables. Sin embargo se sabe de su incursión como trabajador en las minas de carbón, muy probablemente en la zona industrial del Ruhr, aunque dice haber trabajado también en minas de Bélgica y Francia, lo cual no consta que haya sucedido realmente. 
Sachlichkeit (Nuevo Objetivismo), a la que podrían hacérsele las mismas acusaciones que Lukács hace al naturalismo. De acuerdo con la teoría lukacsiana, el verdadero arte realista es aquel que, independientemente de las ideas políticas del autor, refleja una imagen fiel a la realidad en cuanto a que, de manera dialéctica, logra interpretar los vínculos entre la apariencia superficial y la esencia en su campo histórico, y que siempre esta realidad reflejada está fuertemente vinculada con los aspectos éticamente progresistas del autor (LUKÁCS, 1968).

Sostenemos que en las imágenes presentadas por Zech en estos poemas se construye, a partir de la forma poética que adoptan, de su expresión formal y sus recursos retóricos, una textura en la que la esencia del ámbito representado se expresa en la superficial apariencia del objeto mostrado por el poema (o bien, del objeto-poema) y, a su vez, esa apariencia, en su desenvolverse poéticamente, revela la esencialidad de la que desprende.

\section{El minero}

El ancho pecho alzado por la disnea, así conduce férreas estacas golpe a golpe a través de la roca, hasta que del salto de bloques inunda el túnel el polvo que borbotea.

En los fogonazos cintilantes de la luz del foso reluce cual metálico el desnudo cuerpo; gotas de sudor bajan, como perlas cayendo desde los poros bien abiertos del rostro.

Tararea el minero, al compás del martillo y al juego del picudo hierro, una tonta canción y sólo cesa, como por súbito susto sobrecogido,

cuando, en la perforada galería, a lo lejos retumban detonaciones como truenos, y cesa y deja tres veces girar el farol.4

El poema presentado en forma de soneto5, con la arquitectura rítmica y estrófica que le dan cohesión, el juego de contrastes: el trabajo ligado a lo pétreo, férreo y polvoriento versus la perla del sudor del minero (cuya brillante

\footnotetext{
4 Las traducciones de los poemas de este libro de Zech son nuestras.

5 Estos sonetos de Zech, poeta que supo manejar con maestría las formas clásicas, presentan sin embargo una serie de operaciones realizadas sobre sus estructuras métricas y rítmicas que, sin desdeñar la tradición sonetística de la lírica alemana, introduce en ella variaciones que, creemos, aportan a la expresividad poética del libro que conforman. Es necesario considerar también que estos poemas se insertan, indudablemente, en el período expresionista de Zech, corriente para la cual el recurso a las formas tradicionales a la vez que la puesta en tensión de las formas clásicas fue una de sus características principales, en su vertiente lírica al menos. Por lo demás, no constituye éste un aspecto sobre el que corresponda explayarse aquí.
} 
blancura podríamos adivinar brillando contra el tizne del hollín y el carbón), la banalidad de la canción tarareada en contraposición a la siniestra detonación que a lo lejos amenaza con la opresión de la montaña que puede derrumbarse sobre el minero en cualquier momento; todo esto constituye la expresión de una esencia subyacente que se manifiesta en la imagen presentada por el poema y que va a tomar densidad en su vínculo con los demás poemas del libro:

\section{Bajada}

De rudas púas dentado el roblizo portal se sale reticente de los tirantes de hierro. Pesadas taconean, sobre adoquines negros, muchas botas claveteadas un terrible compás.

Se aprieta espantada, como un rebaño, la cuadrilla en la luz helada de las lámparas, tropieza somnolienta en alabeadas rampas hasta que con sofoco la acoge en el atrio el vaho.

La carga desplegada el capataz inspecciona y mecánicamente lee -y con voz de mandolos nombres anotados, de la lista.

Luego, sobre tableados, raudal de vapor rechina $y$, de diez en diez en jaulas, hacinados, hacia el pozo, la soga los arroja.

La concepción presentada sobre el Dinggedicht nos permite pensar en una dialéctica de forma y contenido en la que la realización material en la materia versal, es decir, la realidad reflejada en el poema, cobra vida como objeto-poema y, a la vez, la pura puesta en práctica de las técnicas, los recursos a la tradición poética adquieren sentido a partir del contenido que sustentan. ${ }^{6}$ Así aparece el poema como artefacto presentador o representador de una realidad determinada. Podemos proponer que Zech busca presentar en el entramado constituido por estos poemas las relaciones humanas del sistema productivo en cierta esfera de la productividad paradigmática de principios de

\footnotetext{
${ }^{6}$ Por motivos de extensión tratamos aquí sólo cuestiones generales acerca de estas técnicas formales que utilizan los poemas, pero si nos adentráramos en los poemas en su lengua original, podríamos hacer un análisis de los recursos rítmicos y fonéticos con cuyo "ajustado despliegue" Zech "presenta" el objeto. Sólo por mencionar un ejemplo, en los últimos dos tercetos de "El minero" (Der Hauer), el juego del Stabreim (rima aliterante de principio de palabra) y el impulso rítmico hacia el ritmo trocaico sustentan el "compás del martillo" y el tarareo del minero, y ritman la escena que se desarrolla en el túnel de la mina: Der Hauer summt ein dummes Lied zum Takt / des Hammers und zum Spiel der spitzen Eisen / und stockt nur, wie von jähem Schreck gepackt, // wenn hinten weit im abgeteuften Stollen / Sprengschüsse dumpf wie Donnerschläge rollen, / und stockt und lässt die Lampe dreimal kreisen.
} 
siglo en Europa, exponiendo los vínculos de opresión y de explotación que allí se dan.

\section{El agitador}

Cabeza a cabeza: sobre tejuelas, albas fases lunares. Acecha la porfía como homicidio en todas las caras. Un extraño hirsuto de frente estrecha tiene la primera palabra

y pone el brazo cual honda de David contra gigantes.

Mas su voz: de tubo de órgano tierna introducción, prueba primero el fervor de los reunidos en la sala. Luego, como coral luterano, truenan aludes de palabras monte abajo, para tensar del todo la excitación.

Y este estremecimiento, al que nada inhibe y nada subyuga, asola la defensa tensa de las caras

hasta que un desangrar seso a seso inunda como locura.

Y, encendida de rabia, estridente en deseos de huelga, se va en siseo la convulsión de las lámparas $\mathrm{y}$, tres veces ardiendo hacia la noche, empuja la revuelta.

El héroe, o el personaje tipo de la realidad reflejada en el libro, el minero, inserto en su contexto de trabajo, sometido a las precarias condiciones del trabajo en la mina. Luego, el minero en el contexto de trabajo junto sus pares, presentados como un "rebaño" entrando a la mina ante la mirada vigilante del capataz. Por último, trajimos aquí el poema del agitador a la huelga, que introduce la dimensión sindical en la que el proletariado en unión con sus pares intenta pugnar por sus derechos y sus condiciones de trabajo. Asimismo, en el libro aparecen también los burgueses propietarios, el esquirol, las familias de los obreros y el espacio urbano que habitan. Cada uno de estos elementos -que por motivos de extensión no podríamos traer uno por uno aquí- son presentados por medio de este artefacto poema-objeto cuya constitución, en la que forma y contenido se vinculan dialécticamente para reflejar un fragmento determinado y elegido de una realidad, va construyendo un tejido social, elemento constitutivo a elemento constitutivo, mostrando los tipos y la complejidad del contexto, penetrando en la apariencia para, a cada momento, hacer brillar la esencia de esa realidad en cada objeto-poema presentado.

Lukács (1968) plantea que:

El tipo se caracteriza por el hecho de que en él concurren todos los rasgos predominantes de aquella unidad dinámica en la cual la auténtica Literatura refleja la vida, de que estas contradicciones, las más importantes contradicciones sociales, morales y espirituales de una época se conjugan en una unidad vital. (...) En la representación 
del tipo en el arte típico se unen lo concreto y lo legal, lo eternamente humano y lo históricamente determinado, lo individual y lo socialmente general. (pp. 220-1)

Decir, por lo tanto, que los personajes de los poemas de Das schwarze Revier se condicen estrictamente con este concepto de tipo sería sin dudas arriesgado, pues, si bien podría aplicarse aquello de "lo eternamente humano y lo históricamente determinado", considerándolo en términos de los vínculos productivos en un contexto particularmente industrializado como es el de la Alemania de los años previos a la I Guerra Mundial, parecieran ser estos personajes más bien planos con respecto a la parte de la definición que se refiere a las "contradicciones sociales, morales y espirituales de una época". No hay en ellos, por lo que podemos ver en los poemas citados, grandes contradicciones en los personajes, se trata más bien de caracteres estereotípicos. Sin embargo, el valor que encontramos en estos poemas a este respecto es el de la textura, el del tejido social que en su vinculación a lo largo del libro van constituyendo como un reflejo particular de una realidad determinada.

Unos 20 años después, Zech llegaba a la Argentina y mostraba, en un texto genéricamente distinto -además de autobiográfico-, un personaje más cargado con las contradicciones que su propia situación personal le aportaban: Quien, en momentos de desasosiego, se vea obligado a reflexionar con absoluta claridad sobre su destino futuro, tras haber reconocido finalmente que ya no puede respirar el aire de su entorno, quizá recuerde, cuando ya no encuentra otra salida que la de apartarse violentamente de esta vida, algún parentesco en el mundo. Y cuando esta imagen ya un tanto difuminada reaparece de golpe con toda frescura y tiene el contorno de una certeza inmediata, la fuerza del recuerdo se extiende un poco más. Y uno intenta descifrar lo vivo detrás de la apariencia y conocer el sentido más profundo del vínculo de parentesco. (1997, p. 19)

Este texto ensayístico está dividido en tres partes, la primera comienza con la imagen de desasosiego e incertidumbre ante la inminencia del viaje del fragmento recién citado y se explaya en las ideas previas que tiene sobre el país al que ha de llegar y las imágenes idílicas con las que se lo imagina:

a un par de jornadas de aquí uno ya puede establecerse junto a la fuente primitiva de todo lo que nutre, de todo lo que fluye y lo que crece. Donde la tierra aún tiene muchísimo espacio para todo excedente de seres humanos y de la obra de sus manos productoras (1997, p. 20) [las cursivas son nuestras].

Es el lugar en el que está todo aún por hacerse y desde el que los granos, los animales, la materia prima parten

Hacia un mundo que hace mucho que ya no tiene ese viento, ese bosque, esos campos de pastoreo y las fuerzas extraídas de ese paisaje nutritivo. Y que por eso debe desmoronarse, sobre sí mismo, 
bajo las manifestaciones críticas de una confusión desorientada (1997, p. 21) [las cursivas son nuestras].

En la visión romantizada de Argentina de un autor alemán que muy en contra de su voluntad debe abandonar su tierra -romantización que entra en crisis en la segunda y tercera parte de este texto- existe también una imagen del sistema productivo mundial y de la división internacional del trabajo de los comienzos de siglo que reflejan una globalización incipiente y una visión desencantada y decadente de la crisis de una Europa que sucumbe ante el fascismo. Frente a esta Europa, con cierta inocencia y aun con cierto orgullo o sensación de superioridad hegemónica, se le figura una imagen de la Argentina como una tierra helénica y sin determinación histórica, como un lugar en el que todo lo que viene causando lo que Zech siente como un fin del mundo, no ha tenido lugar y en donde se va a jugar el futuro del mundo:

Donde a los que ingresan por casualidad, a los que aún no se han asimilado, de ningún modo se les pregunta (...): “¿De dónde vienes? ¿Quién eres?”; pero donde se pretende saber con toda claridad: “¿A dónde vas? ¿Qué sabes hacer?” (...) Una ciudad donde con seguridad todavía no existe mucho de lo que en Europa ya superamos hace tiempo. Pero donde puede decidirse tarde o temprano lo último y tal vez determinante, lo definitivo para el mundo. (1997, p. 20)

Todo el punto de vista autobiográfico de este ensayo es el vehículo de la propia forma que va tanteando, la forma con la que evalúa y pone en consideración una visión determinada del mundo y una lectura del momento histórico. En términos de Adorno:

La referencia a la experiencia (...) es la referencia a la historia entera; la mera experiencia individual, con la que la conciencia arranca y empieza como con lo que más próximo le es, ya está mediada por la experiencia comprehensiva de la humanidad histórica... (1962, p. 20)

La experiencia propia, narrada y reflexionada y el ordenamiento por momentos caprichoso de las ideas y las impresiones reflejan -en la superficie de su expresión- el desencanto que cunde en un mundo en crisis y al borde de una guerra y que se constituye en algo así como su tónica.

De esta forma, podríamos proponer que un escritor intelectual de izquierda se aparece aquí como carácter tipo de la sociedad europea del siglo $\mathrm{XX}$, que reflexiona sobre el contexto de su exilio, una clase de emigración cuya especificidad radica en los motivos políticos de la huida7:

Así se erigía, en estas consideraciones previas, la ciudad ante él, ante

7 Arnold Spitta define que "El exiliado ha sido obligado a la fuga (o emigración) a causa de su propio accionar político o bien sus visiones políticas. Él es el refugiado político en sentido estricto. El emigrante, en cambio, debió abandonar su terruño por causas que fueron independientes a su posición o actividad política (por ejemplo, persecución racial)." (la traducción es nuestra) (1978, pp. 8-9). 
el hombre que sólo era uno entre muchos semejantes cuando un día se le quitó no sólo el sentimiento de terruño y la patria, sino además el suelo que lo nutría y la libertad personal en todas sus manifestaciones. (1997, p. 21)

La segunda y la tercera parte del ensayo se ocupan ya de sus primeras impresiones sobre la Argentina. Primero de aspectos urbanísticos de la ciudad de Buenos Aires, la publicidad radial y la colectividad alemana, y luego de aspectos artísticos de la cultura local, principalmente de la literatura y del teatro.

En la primera de estas partes, pareciera ser que las impresiones que recibe Zech sobre esta tierra son tantas y tan intensas que el tono se vuelve más vertiginoso, más cáustico y el estilo parece recordar al de su propio expresionismo más temprano (el de los poemas a los que nos referimos más arriba, pero también a otros poemas de los primeros años en los que retrata escenas del ámbito portuario), pues pareciera ser que tal es la impresión que esta ciudad le genera:

Y ante la verja, en medio de la trajinada acera, una vieja figura humana llena de costras, repleta de harapos y mugre: una mujer de ochenta años, durmiendo con una bolsa de mendigar debajo de la cabeza.

Y, además, el olor del mar, el murmullo en el viento y las poderosas masas de agua en el semicírculo del horizonte. Con barcos que entran y vuelven a partir. Con el chirrido de las cadenas de las anclas y de las grúas correderas. Con un muelle negro por el hormiguero humano... (1997, p. 23)

El prejuicio idílico de una tierra helénica de la modernidad -valga lo paradójico de la expresión- se choca con las contradicciones del subdesarrollo:

Y así como en todas las partes del territorio sudamericano las calles son sólo el letrero de las fuerzas en actividad, oscilando inquietas por las gradaciones de la tensión económica y los estratos sociales, y también el indicador vibrante de aquello que uno quisiera parecer pero que aún no ha llegado a ser realmente, a menudo muy bien encaminado hacia allí, pero constantemente separado por la irrupción inesperada de malas coyunturas y devaluación monetaria, revoluciones e intranquilidad en las provincias, así también aquí, en el amontonamiento de casas de una planta, de construcción morohispana, a menudo muy primitivas y semiarruinadas, junto a rascacielos de 38 pisos, obras en construcción baldías durante años y ruinas de un inquilinato demolido, alineados en una sola calle como la configuración viva de la apariencia: rica y pobre, proletaria y ultracapitalista, archiconservadora y aventurera al borde de la especulación más osada. (1997, p. 22)

En esta etapa de su obra, Zech parece más afectado por los aspectos contradictorios de la sociedad. De la publicación de Das schwarze Revier al ensayo Buenos Aires (1935) pasaron 22 años y no solamente es distinto el 
contexto de escritura sino también -y fundamentalmente- la posición en la que el autor se ubica frente a éste. En 1913 parecía tratarse de un Zech más preocupado por retratar el mundo de los oprimidos; esto era acorde a su posicionamiento político, su pertenencia (o al menos acercamiento, pues no hay datos exactos al respecto de su afiliación) al SPD (Sozialdemokratische Partei Deutschlands, Partido Socialdemócrata Alemán) y posteriormente al USPD (Unabhängige Sozialdemokratische Partei Deutschlands, Partido Socialdemócrata Alemán Independiente -que se asocia con la Liga Espartaquista) y las perspectivas de una revolución socialista. Podríamos proponer que se trataba entonces de una poesía de carácter más militante. Mientras que en esta otra etapa, luego de haber sido derrotada la revolución en Alemania, luego de la experiencia de la República de Weimar, las dificultades económicas y el exilio, se abre a un autor veinte años más maduro un mundo absolutamente nuevo al que llega un poco a regañadientes y donde la necesidad literaria es otra. Entonces, tanteando ${ }^{8}$ aquí la forma del ensayo intenta dar cauce a esta serie arrobadora de impresiones novedosas e inesperadas, donde lo contradictorio, lo fragmentario y lo discontinuo se vuelve la expresión formal del discurso. Adorno (1962) plantea sobre la forma del ensayo que su fragmentariedad es comparable a la del romanticismo, a la "concepción romántica del fragmento, como formación incompleta que procede al infinito a través de su autorreflexión” (p. 27). Esta idea es de suma importancia para la estética marxista: lo fragmentario como exponente de lo total, y "que la totalidad brille por un momento en un rasgo parcial escogido o alcanzado, pero sin afirmar que la totalidad misma esté presente” (p. 28), que lo fragmentario que se muestra como superficial sea la arena en la que lo esencial y subyacente se debate, y que haga emerger eso esencial y subyacente para que se vuelva apariencia de otra esencia. Benjamin, asimismo, se refiere al montaje de los harapos o de los desechos de la historia:

Esto es, levantar las grandes construcciones con los elementos constructivos más pequeños, confeccionados con un perfil neto y cortante. Descubrir entonces en el análisis del pequeño momento singular, el cristal del acontecer total. Así pues, romper con el naturalismo histórico vulgar. Captar la construcción de la historia en cuanto tal. En estructura de comentario - Desechos de la historia. (2005, p. 463)

Como si fuera por entre las coyunturas de los fragmentos, en lo fragmentario (en la sucesión de imágenes de la enumeración, en la concatenación de ideas o en el montaje de los desechos) se filtra la esencia de una modernidad iridiscente, multívoca y polifónica, y en lo contradictorio del entretejido social expresado como superficie, como apariencia, se ven

\footnotetext{
8 Adorno dice al respecto de la manera en que el ensayo procede que "no lo hace programáticamente, sino como caracterización de la intención tanteadora” (1962, p. 28);
} 
reflejadas las fuerzas subyacentes de la realidad que constituyen su esencia. Así, prolifera también Zech en momentos por la vía de la enumeración:

Rostros de marfil oliva y ébano. Inmigrantes con todos sus trastos, charlatanes y timadores. Mercachifles cargados de artículos para fumadores, caramelos $^{9}$, naranjas y tortas de maíz rellenas con carne. Griterío ensordecedor de los vendedores de diarios, niños: andrajosos, sucios, la negra gorra de plato llevada don descaro sobre la oreja y el eterno cigarrillo entre los dientes. Ejércitos de lustrabotas, tranvías taxis, colectivos y un niño perdido, el mismo que llora siempre y en todas partes. Una magnífica vista, este trozo de puerto, las calles paralelas, rozadas por el follaje sereno de invierno, acariciadas por un aire templado, absolutamente limpio. (1997, p. 24)

En la última parte del ensayo, Zech se ocupa principalmente del ámbito literario y teatral local. Incurre en una diatriba en contra de una cultura para la cual el modelo es el francés y que es propiedad de una clase alta; menciona algunos diarios y publicaciones como Sur, que "Lamentablemente aparece casi a puertas cerradas, como placer privado de una rica dama con ambiciones literarias, que se siente más en casa en París y Roma y Londres que en Buenos Aires" (1997, p. 28).

Más allá de su cáustica descripción de la escena local, resultan interesantes en esta parte ciertos elementos que nos construyen el contexto histórico. En cuanto a Alemania, se nos figura un estado particular de la globalización y de la división internacional del trabajo en un momento en que los movimientos migratorios marcaban una productividad específica, pues:

Alemania jamás ha sido para esta gente latinoamericana un concepto político relevante. Más bien ha sido un objeto de intercambio mercantil y de mano de obra especializada barata y voluntariosa. (1997, p. 26)

Asimismo, la amenaza del fascismo parece la confirmación de un estado globalizado del mundo en el que ni el exilio termina de poner distancia ante aquello de lo que se huye. Zech refiere a una puesta en escena de la obra de teatro Razas, del antifascista Ferdinand Bruckner (seudónimo del dramaturgo Theodor Tagger), en la cual irrumpieron representantes del sector fascista de la colectividad para protestar

contra el "ultraje de los emblemas alemanes (léase la canción de Hosrt-Wessel), la difamación del Führer y la denigración del pueblo alemán", lo cual condujo finalmente al cierre temporario del teatro. Después de este "asalto al teatro" y de esa "batalla teatral", hay que poner absolutamente en duda que estos descarados escándalos, inspirados, puestos en escena y financiados por la conducción local del partido nacionalsocialista alemán, resulten absolutamente útiles al prestigio del pueblo alemán. (...) Y una vez más es necesario

${ }^{9}$ Las cursivas están indicando que Zech usa esta palabra española. 
concluir una consideración que tenía que ver con asuntos totalmente distintos del mundo en torno a la esvástica, constatando que, incluso separados por el océano, cerca de la selva, bajo un sol tropical abrasador, en una ciudad donde los últimos vástagos indígenas se mezclan con las razas blancas de Europa, uno no puede librarse de ese escalofriante lastre (1997, pp. 30-1).

El mundo ahora reflejado se llena de los conflictos y contradicciones que le dan una densidad particular al texto. $\mathrm{Y}$ en el texto se entretejen las fragmentarias impresiones y las ideas, debatiéndose en la arena de la expresión que tantea buscando la connivencia dialéctica en la que la superficie del texto pone en marcha la esencia subyacente de un mundo nuevo que todavía pugnaba por adquirir, para Zech, una expresión.

Esperemos valgan, entonces, estas ideas aquí propuestas para introducir la obra de un autor aún poco estudiado en nuestra lengua al horizonte teórico de la estética marxista. Consideramos que su obra puede ser de gran provecho para el estudio de la literatura alemana en el contexto del exilio en Latinoamérica y que, a su vez, una perspectiva marxista es más que propicia (y creemos que novedosa) para su análisis, a la vez que esperamos que la obra de Zech pueda aportar al estudio de la estética marxista.

\section{Referencias bibliográficas}

ADORNO, Theodor. Notas de literatura. Barcelona: Ariel, 1962. BENJAMIN, Walter. El libro de los pasajes. Madri: Akal, 2005. LUKÁCS, György. Sociología de la literatura. Barcelona: Ediciones Península, 1968.

OVERATH, Angenlika. Das andere Blau: Zur Poetik einer Farbe in modernen Gedicht. Stuttgart: J. B. Metzler, 1987.

PICCOLI, Héctor. Prólogo. In: ZECH, Paul. Yo soy una vez Yo y una vez Tú: Antología poética. Rosario, Argentina: Editorial Serapis, 2010.

SPITTA, Arnold. Paul Zech im südamerikanischen Exil 1933-1946. Berlim: Colloquium Verlag, 1978.

ZECH, Paul. Das schwarze Revier. Berlim: A.R.Meyer Vlg., 1913. . La Argentina de un poeta alemán en el exilio 1933-1946. Buenos Aires: Facultad de Filosofía y Letras UBA, 1997. 
Como citar:

SUFOTINSKY, Tomás. La configuración de la realidad en dos momentos de la obra de Paul Zech. Verinotio - Revista on-line de Filosofia e Ciências Humanas, Rio das Ostras, v. 26, n. 1, pp. 203-15, jan./jun. 2020.

Data do envio: 14 mar. 2020

Data do aceite: 4 maio 2020 